\title{
Medical History Domain
}

National Cancer Institute

\section{Source}

National Cancer Institute. Medical History Domain. NCI Thesaurus. Code C49603.

A subject domain utilized for the submission of information encompassing and

representing data, vocabulary or records related to subject medical history. 